\title{
On the Influence of Children's Sports Dance on Their Physical Fitness and Psychological Behavior Problems
}

\author{
Guo Min-gang ${ }^{1, *}$ and Bian Dan-dan ${ }^{2}$ \\ ${ }^{I}$ Physical Education Department of Wuhan University of Technology, Wuhan 430070, Hubei, China; ${ }^{2}$ The Kindergarten \\ of Wuhan University, Wuhan 430072, Hubei, China
}

\begin{abstract}
To explore the influence of children's sports dance on the physical fitness and psychological behavior problems of children in different school period, this paper adopts literature research, teaching experiment, and mathematical statistics, to study the influence of introducing children's sports dance to the class on their physical fitness and psychological behavior problems. The research results show that children's sports dance practice can not only effectively promote the improvement of physical fitness of children in different school period, but also improve their psychological behavior problems, which is worth introduction and promotion in the kindergarten.
\end{abstract}

Keywords: Children's sports dance, children, physical fitness and psychological behavior problems.

\section{INTRODUCTION}

The research of children's physical fitness and psychological behavior problems has drawn high attention of professionals of education, physical geodesy, psychology, and medical care at home and abroad. Among them, there are some representative research results: (1) Zhu Mingqing's research on the relationship between father's education level and the children's physical fitness points out that except sitand-reach and balancing beam, children whose father's education level are higher are better in other aspects than children whose father's education level are lower [1]. (2) Li Mailang carried out the research on children's physical fitness measurement and evaluation, which established a relatively complete children's physical fitness measurement and evaluation system based on the norm reference indicators after two measurements, and provided suggestions to the public children's physical fitness measurement and evaluation in kindergarten [2]; (3) Wang Yuqing points out in her Relationship between Children's Psychological Theory and Metacognition that, there is high coorelation between the children's psychological theroy and metacognition of children from 3 to 5 years old [3]. However, existing research rarely involves the comprehensive influence of aerobic exercise intervention on the physical fitness quality and psychological behavior problems $[5,6]$. Therefore, this study tries to comprehensively reveal the influence of children's sports dance on the physical fitness quality and psychological behavior, through teaching children's sports dance course.

\section{EXPERIMENT METHODS}

\subsection{Objects}

60 cases of children from 3 to 6 years old in top, middle, and bottom classes in Wuhan University Kindergarten

*Address correspondence to this author at the Physical Education Department of Wuhan University of Technology, Wuhan 430070, Hubei, China; E-mail: thepsb02@sina.com
Branch 1 are selected as the objects of this research. They are randomly selected with 20 cases in each school period with the same sex ratio. The samples are divided into experimental group and control group. The control group (30 boys and girls from top, middle, and bottom classes) was taught in traditional way, while the experimental group (30 boys and girls from top, middle, and bottom classes) was taught by the combination of traditional teaching and children's sports dance. To control and reduce the error, the teachers are from the research group. At the same time, professional children's physical fitness testers are hired to measure various physical fitness indicators before and after experiment. Children's psychological behavior problems are measured by revised Achenbach child behavior scale in China [4]. The Scale distribution and recycling are managed by one teacher with the scales filled out by the guardians or parents of the children.

\subsection{Research Tools}

\subsubsection{Test Scale}

This research adopts the revised Achenbach child behavior checklists (CBCL) as the test scale. 113 entries in the children's behavior problems in the scale are selected and divided into 8 factors, including sample split, depression, disciplinary violation, aggressive behavior, body presenting, social withdrawal, immature, and sexual problems. Each item is scored based on the performance of the samples in recent half a year, using three-level criteria of 0,1 , and 2 . According to the Chinese Norm of children behavior problem standards promulgated by Liu Ling in 2003 and Qi Ren'e in 1992, the factor with total score larger than the norm level is regarded as a problem. The homogeneity reliability of the scale (Alpha coefficient) is 0.92 , which is conform to the requirements of the statistics.

\subsubsection{Main Test Indexes}

The National Physical Fitness Determination Standard (children's part) issued by the state general administration of 
Table 1. Class, age, and gender of objects.

\begin{tabular}{|c|c|c|c|c|c|}
\hline Top class & $60 \sim 70$ & 64 & 10 & 10 & 20 \\
\hline Bottom class & $36 \sim 42$ & 40 & 10 & 10 & 20 \\
\hline
\end{tabular}

sports in 2003 is referenced for the screening standard of the indicators of children's fitness [7].

Quality indicators: Standing long jump, crook proneness, $10 \mathrm{~m}$ reverse layup, balance beam, and double feet consecutive jump Table 1.

Main indicators for psychological behavior problems: Split sample, depression, disciplinary violation, aggressive behavior and sexual issues.

\subsubsection{Test Implementation}

Children's physical fitness test is strictly in accordance with the detailed rules and regulations of national physical fitness monitoring work and the requirements of quality supervision [8]. For children's psychological behavior problems test, the revised children behavior scale is sent out to the parents for evaluation. The items in the scale is scored based on the behavior in the recent six months ( 2 points for obvious or frequent behaviors, 1 point for sometimes, and 0 point for never or seldom). The scales will be completed by the children's parents in the kindergarten, with the interpretation and guidance of the members in the research team to ensure the accuracy and reliability of the contents. Group leader of each grades in the kindergarten will be responsible for giving out and reclaiming the scales.

\subsubsection{Experiment Design}

After testing the children's physical fitness indicators, children in the experimental group will be taught with children's sports dance during extracurricular activity time besides the traditional contents regulated in the Kindergarten Curricular. The children's sports dance is revised based on the children's collective dance example of Sanna Longden, an American children's sports dance expert, with the combination of the physical characteristics of the children (5 times a week, and 30 minutes each time). The design of children's sports dance curriculum includes warm-up exercise, basic dance movements exercise, and relaxation, with children's dancing music as company. Children in the control group will be study and exercise completely in accordance with the provisions of the kindergarten curriculum, with their extracurricular activities in accordance with the general requirements of the kindergarten.

\subsubsection{Experimental Condition Control}

During the experiment process, children's sports dance teachers of the objects will be undertaken by young backbone teachers of Wuhan University Kindergarten Branch One, to ensure that the children sports dance course can be scientific and effective for the achievement of the experimental purpose. During the whole experiment process, we will seek for the support and cooperation of kindergarten leaders, teachers, and children's parents. In order to reduce experimental error, except for the extracurricular activities, other activities in the kindergarten should be the same for children in the experimental group and control group. The other conditions should be the same to make sure there are no difference in diet, living habits, and extracurricular between the two groups.

\subsubsection{Experiment Time}

This experiment lasts for a semester, the first test time (before experiment) is August 31, 2012, and the second test time (after experiment) is January 31,2013 . This experiment time is set for a semester for the following two reasons: first, a large number of studies show that long-term adherence to the regular aerobic exercise has an remarkable effect on human health of body and mind, while short-term irregular aerobic exercise has little effect; second, experiment in children's normal teaching time facilitate the implementation and operation, to control the interference of irrelevant variables on the experimental results and reduce experimental error.

\subsubsection{Experiment Results Treatment}

The experiment data is entered by professionals and processed by SPSS17.0, to get the mean value $(+/-)$ and standard deviation $(\bar{x} \pm s)$ of each indicator. Differences between groups adopt independent sample $t$ test. Differences in the group before and after the experiment adopt paired t test, with $\mathrm{p}<0.05$ referring to significant difference and $\mathrm{p}<0.01$ referring to very significant difference.

\section{EXPERIMENT RESULTS}

\subsection{Influence of Children's Sports Dance on Physical Fit- ness Quality of Children in Different School Age Period}

Main physical fitness quality indicators of the control group changed significantly before and after experiment, with $\mathrm{p}<0.05$.

After a semester of children's sports dance source, children in the experimental group show significant differences from before. The standing long jump indicator increases significantly, with significant difference $(\mathrm{p}<0.05)$, Crook proneness and balance beam indicator rise very significantly, with very significant difference $(p<0.01)$. 10 meters running back and forth indicator decreases significantly, with significant difference $(\mathrm{p}<0.05)$.

Compare the test results of children in the experimental group and control group in the same grade of the same test, there are very significant differences in crook proneness and balance beam, with $\mathrm{p}<0.01$; and there are significant differences in 10 meters running back and forth and standing long jump, with $\mathrm{p}<0.05$. 
Table 2. Mean physical fitness indicators of subjects before and after experiment $(\bar{x} \pm s)$.

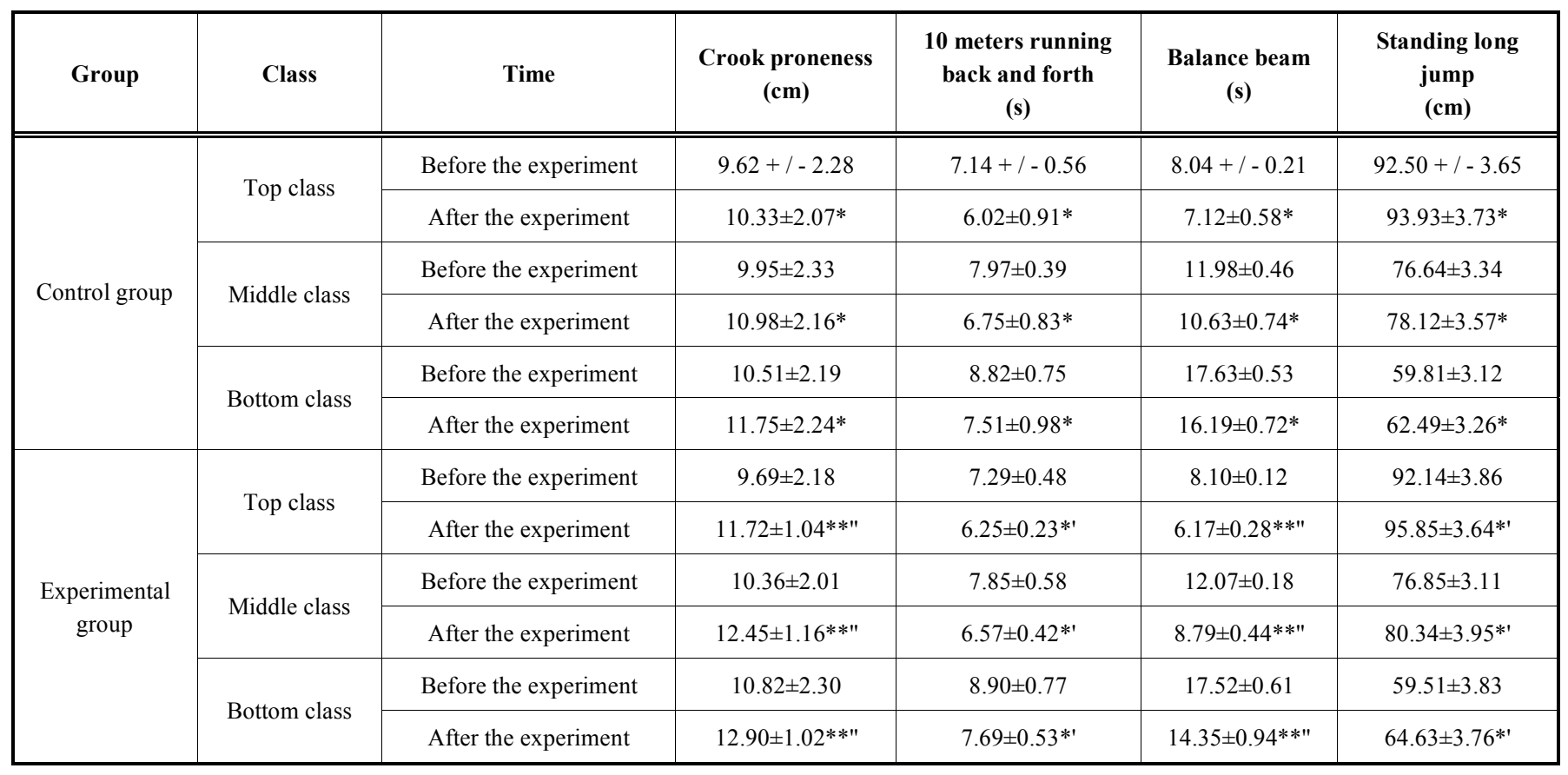

Note: $\backslash$ Comparison of test results before and after experiment: $* \mathrm{P}<0.05, * * \mathrm{P}<0.01$; Comparison of test results of both groups of the same grades in the same test: 'P $<0.05$; $\mathrm{P}<$ 0.01 .

\subsection{Influence of Children's Sports Dance on Psychologi- cal Behavior Problems of Children in Different School Age Period}

Before the teaching experiment, the researchers carried out psychological behavior problems screening of all subjects. Based on the total score, 11 of them are beyond the range of Chinese norm ( 6 boys and 5 girls), in which boy's behavior problems detection rate is $20 \%$, the girl's behavior problem detection rate is $16.7 \%$, and the total detection rate is $18.3 \%$. The result is significantly different from the existing result of about $14 \%$ for children from 4 to 5 years old. This may be because of the small sample size of this research or the increasingly severe situation of children's psychological problems in China. Zang Yuling, a child psychology expert pointed out that the increasing trend and high incidence of children's psychological deviation should draw common attention from education department and the society.

In order to explore the influence of children's sports dance on psychological behavior problems of children in different school age periods, the author conducted statistical processing to change of five indicators of children's psychological behavior problems before and after the experiment (see Table 3). The result shows that, the aggressive behavior, split sample, sexual problem, depression, and discipline violation of the control group after experiment decreased than before, among which, indicators including aggressive behavior, depression, and discipline violation show significant difference $(\mathrm{P}<0.05)$. The aggressive behavior, split sample, sexual problems, depression, and discipline violation of the experimental group after the experiment are decreased than before. Among which, aggressive behavior, depression, and discipline violation show very significant difference $(\mathrm{P}<$
$0.01)$, while split sample and sexual problems show significant difference $(\mathrm{P}<0.05)$. The test result of both groups of the same grade in the same test shows that the difference in aggressive behavior, depression, and discipline violation is very significant $(\mathrm{P}<0.01)$, while the difference in split sample and sexual problem is significant $(\mathrm{P}<0.05)$. In addition, as is shown in Table 4, after a semester of children's sports dance intervention, the CBCL score of the experimental group is decreased significantly, with very significant difference $(\mathrm{P}<0.01)$, while the CBCL score of the control group is slightly down, with significant difference $(\mathrm{P}<0.05)$.

\section{DISCUSSION}

This study points out that children's sports dance plays a positive role in the improvement and elimination of children's physical fitness quality and psychological behavior problems of children of different school age periods.

\subsection{Children's Sports Dance has Intervention Effect to the Physical Fitness Quality of Children of Different School Age Periods, with Different Levels}

Under the condition of this experiment, the intervention effect to the children in the experimental group is more significant. As is shown in Table 2, the physical fitness quality indicators of the control group shows no significant changes except for the significant increase in standing long jump. However, crook proneness, 10 meters running back and forth, balance beam, and standing long jump for the experimental group are significantly improved, among which, crook proneness and balance beam increase very significantly $(\mathrm{P}<0.01)$. The reason is: first, the children's sports dance course is designed based on the characteristics of the children. The dance movements are good for the flexibility 
Table 3. Mean value of children's psychological behavior problems of the subjects before and after experiment $(\bar{x} \pm s)$.

\begin{tabular}{|c|c|c|c|c|c|c|c|}
\hline Group & Class & Time & Aggressive & Split sample & $\begin{array}{c}\text { Sexual prob- } \\
\text { lems }\end{array}$ & Depression & $\begin{array}{c}\text { Disciplinary } \\
\text { violations }\end{array}$ \\
\hline \multirow{5}{*}{ Control group } & \multirow{2}{*}{ Top class } & Before the experiment & $5.35 \pm 4.59$ & $1.79 \pm 1.36$ & $1.52 \pm 2.20$ & $1.53 \pm 1.49$ & $1.00 \pm 1.72$ \\
\hline & & After the experiment & $4.95 \pm 4.38^{*}$ & $1.68 \pm 1.43$ & $1.35 \pm 1.12$ & $1.14 \pm 1.23^{*}$ & $0.54 \pm 2.07 *$ \\
\hline & Middle class & Before the experiment & $4.67 \pm 3.56$ & $1.57 \pm 0.94$ & $1.38 \pm 2.07$ & $1.36 \pm 0.99$ & $0.82 \pm 1.30$ \\
\hline & \multirow{2}{*}{ Bottom class } & Before the experiment & $3.61 \pm 3.04$ & $1.12 \pm 1.22$ & $1.05 \pm 1.13$ & $1.24 \pm 1.30$ & $0.94 \pm 1.15$ \\
\hline & & After the experiment & $3.07 \pm 2.79 *$ & $1.03 \pm 0.94$ & $0.85 \pm 0.92$ & $0.77 \pm 0.86^{*}$ & $0.46 \pm 0.87 *$ \\
\hline \multirow{4}{*}{$\begin{array}{l}\text { Experimental } \\
\text { group }\end{array}$} & \multirow{2}{*}{ Top class } & Before the experiment & $4.86 \pm 4.53$ & $1.74 \pm 1.27$ & $1.49 \pm 1.05$ & $1.20 \pm 1.34$ & $0.98 \pm 2.01$ \\
\hline & & After the experiment & $3.51 \pm 2.73 * * "$ & $1.32 \pm 0.83 * 1$ & $0.96 \pm 0.90^{* \prime}$ & $0.52 \pm 0.75 * * "$ & $0.35 \pm 1.87 * * "$ \\
\hline & \multirow{2}{*}{ Bottom class } & Before the experiment & $3.12 \pm 2.53$ & $0.99 \pm 1.02$ & $0.88 \pm 1.01$ & $0.81 \pm 0.79$ & $0.54 \pm 0.77$ \\
\hline & & After the experiment & $2.25 \pm 1.94 * * "$ & $0.61 \pm 0.75^{* \prime}$ & $0.49 \pm 0.91^{* \prime}$ & $0.26 \pm 0.57 * * "$ & $0.16 \pm 0.63 * * "$ \\
\hline
\end{tabular}

Note: $\backslash$ Comparison of test results before and after experiment: ${ }^{*} \mathrm{P}<0.05, \quad{ }^{*} \mathrm{P}<0.01$; Comparison of test results of both groups of the same grades in the same test: 'P $<0.05$; " $\mathrm{P}<$ 0.01 .

Table 4. Total score comparison of achenbach CBCL of children from experimental group and control group ( ).

\begin{tabular}{|c|c|c|c|c|c|}
\hline Group & $\mathbf{n}$ & Before the experiment & After the experiment & t value & P value \\
\hline \hline Control group & 30 & $27.03 \pm 22.42$ & $20.29 \pm 17.41$ & 2.283 & 0.045 \\
\hline Experimental group & 30 & $27.81 \pm 22.76$ & $18.71 \pm 14.37$ & 3.548 & 0.000 \\
\hline
\end{tabular}

and balance of the children; second, it is related to the characteristics of the children. Children are born with better body flexibility [9], which enables easy complete of the children's sports dance movements. The successful experience encourages children to take part in the exercise of children's sports dance actively to promote their physical quality level as a whole.

\subsection{Influence of Children's Sports Dance on Psychologi- cal Behavior Problems of Children in Different School Age Period}

Existing research has confirmed that children's sports dance has positive effect in the improvement of children's psychological behavior problems. For example, Jense \& Kenny's study on boys shows that children's sports dance can improve the impulse, anxiety, and mood swings of children [10]. In this study, the subjects are divided into control group and experimental group [11], with designed children's sports dance classes as the experimental intervention content. The activities of the control group and experimental group are the same except for the designed children's sports dance. Table $\mathbf{3}$ and Table 4 show that, the experiment has significant intervention effect on the psychological behavior problems of children in different school age periods. First of all, from the perspective of the change of children's psychological behav- ior factors, children's sports dance teaching has very significant intervention effect on children's aggression, depression, and disciplinary violation $(\mathrm{P}<0.01)$; and significant effect on split sample and sexual problems $(\mathrm{P}<0.05)$; secondly, from the total score of children's psychological behavior problems, the CBCL score that reflects the severity of children's psychological behavior problems is reduced very significantly $(\mathrm{P}<0.01)$, while the control group is reduced significantly $(\mathrm{P}<0.05)$. Therefore, children's sports dance has significant effect on the improvement of the psychological behavior problems of children in different school age periods.

\section{RESEARCH CONCLUSION AND RECOMMENDA- TION}

\subsection{Conclusion}

The result shows that, children's sports dance course plays a significant role in the improvement of the indicators including crook proneness, 10 meters running back and forth, standing long jump, balance beam, and psychological behavior problems. Therefore, the research suggests that children's sports dance not only can effectively enhance children's physical fitness quality, but also can improve children's psychological behavior problems. 


\subsection{Recommendation}

(1) Kindergartens should open children's sports dance course with developing and utilizing sports dance resources based on the characteristics of children. Latin dance, modern dance, ballet, folk dance, and aerobics can be simplified and revised to be more suitable for the development and characteristics of children, both in physical and psychological.

(2) Higher normal universities and vocational colleges should open related major or course of children's sports dance to lay a foundation for training excellent children's sports dance teachers.

(3) Kindergarten leaders should encourage the teachers to participate in the scientific researches to improve their ability of scientific literacy and education teaching practice, to better guide and support children to learn the children's sports dance.

\section{RESEARCH LIMITATION AND DEFICIENCY}

The limitations of this study are reflected in the following two aspects: on one hand, the samples selected in this study is relatively small. Therefore, the result is limited to a certain degree, with the related data requiring further verification and research. On the other hand, this study did not consider impacts of other intervention factors on the child's physical and psychological behavior problems, such as family education, diet, and sleep condition.

\section{CONFLICT OF INTEREST}

The authors confirm that this article content has no conflict of interest.

\section{ACKNOWLEDGEMENTS}

Declared none.

\section{PATIENT'S CONSENT}

Declared none.

\section{REFERENCES}

[1] M. Zhu, J. Fan, and Q. Luo, "Correlation of father's level of education and children's physical fitness level," Hubei Sports Science and Technology, vol. 28, no. 4, pp. 418-419, 2009.

[2] Gustafson, S. L., \& Rhodes, R. E, "Parental correlates of physical activity in children and early adolescents." Sports Medicine, vol. 36, no. 1, pp. 79-97, 2006.

[3] Y. Wang, and Y. Chen, "Relationship between children's psychological theory and metacognition," Journal of Psychological Science, vol. 2, pp. 319-323, 2008.

[4] J.G. Smetana, M. Jambon, and C. Conry-Murray, "Reciprocal associations between young children's developing moral judgments and theory of mind," Developmental Psychology, vol. 48, no. 4, pp. 1144-1150, 2012.

[5] Z. Li, "Research on physical and psychological health of leftbehind children and non-left-behind children," China's Maternal and Child Health Care, vol. 29, no. 36, pp. 6035-6036, 2014.

[6] W. Xu, "Relationship between children's psychological theory and moral judgment," Chinese Journal of Clinical Psychology, vol. 23, no. 1 , pp. $67-70,2015$

[7] S. Wu, G. Jiang, and S. Zhang, "Research on gross movement development and physical fitness level of children from 3 to 6 years old," Chinese Journal of Child Care, vol. 23, no. 2, pp. 172 $275,2015$.

[8] S. Wu, S. Zhang, and X. Xing, "International comparative study on children's sports and health learning objectives under the perspective of movement development," Journal of Chengdu Sports Institute, vol. 40, no. 5, pp. 75-79, 2014

[9] X. Guan, X. Wang, and G. Wei, "Kinematic analysis of healthy children throwing ability development," Journal of Shenyang Sports Institute, vol. 32, no. 6, pp. 85-88, 2013.

[10] P.S. Jensen, and D.T. Kenny, "The effects of yoga on the attention and behavior of boys with ADHD," Journal of Attention Disorders, vol. 7, pp. 206-216, 2004.

[11] Sallis, J. F., Patterson, T. L., McKEnZIE, T. L., \& Nader, P. R, "Family variables and physical activity in preschool children," Journal of Developmental \& Behavioral Pediatrics, vol. 9, no. 2, pp. 57-61, 1988.

Received: May 26, 2015

Revised: July 14, 2015

Accepted: August 10, 2015

(C) Min-gang and Dan-dan; Licensee Bentham Open.

This is an open access article licensed under the terms of the Creative Commons Attribution Non-Commercial License (http://creativecommons.org/licenses/by-nc/3.0/) which permits unrestricted, non-commercial use, distribution and reproduction in any medium, provided the work is properly cited. 